\title{
Utilizing Analytics to Identify Trends in Residency Program Website Visits
}

\author{
Sean Dyer ${ }^{1}$, Bradley Dickson ${ }^{1}$, Neeraj Chhabra ${ }^{1}$ \\ 1. Emergency Medicine, Cook County Health, Chicago, USA
}

Corresponding author: Neeraj Chhabra, neerajbc1@gmail.com

\begin{abstract}
Introduction

Most medical residency training programs maintain websites to provide content for audiences including current residents, prospective residents, and medical students. This study seeks to characterize when and how a residency program website is being accessed in order to identify the primary audiences to provide appropriate and timely content.
\end{abstract}

\section{Methods}

The authors examined website analytics at a large urban Accreditation Council for Graduate Medical Education (ACGME)-accredited post-graduate year (PGY)1-PGY4 emergency medicine residency training program website. Analytics were performed from July 1, 2016 to June 30, 2018 with daily traffic cataloged along with referral sources, page views, and device type used to access the website. The top five dates by daily traffic were further analyzed with daily traffic trends during the residency interview season.

\section{Results}

There was an average of 45.8 unique visitors daily with 261.5 daily page views. Computer (67.2\%), mobile device (29.6\%), and tablet (3.1\%) were the most common devices used for viewing. The most popular content areas by page-view were "people" (68,987 visits), "home" (38,569), "clinical curriculum" $(35,556)$, and "medical students" (14,461). The five most-visited dates were all related to application processes including the opening of the Visiting Student Application Service (VSAS), the Electronic Residency Application Service (ERAS), and Match Day. During the interview season, peak visits occurred the dates immediately preceding interview dates.

\section{Conclusion}

Residency program websites appear to be accessed most commonly by medical students and prospective residency applicants. Website managers should take the needs of these audiences into account and provide appropriate content to maximally inform prospective residency program candidates.

Received 12/02/2019

Review began 12/30/2019

Review ended 01/28/2020

Published 02/07/2020

๑) Copyright 2020

Dyer et al. This is an open access article

distributed under the terms of the Creative Commons Attribution License CC-BY 4.0., which permits unrestricted use, distribution, and reproduction in any medium, provided the original author and source are credited.

Categories: Emergency Medicine, Medical Education, Healthcare Technology

Keywords: website, residency, application, medical student, emergency medicine

\section{Introduction}

To keep pace with the rapid evolution in web-based communication and marketing over the past three decades, most medical residency training programs have created and maintained program-specific websites. There is considerable variability in the presence and quality of information that is available on these websites, especially as they contend with the need to provide content for multiple different audiences such as current residents, prospective residents, and medical students [1]. In industries outside of medical training, the task of maintaining websites to promote goods and services is a job unto itself that is often subcontracted to third parties and involves entire teams dedicated to uploading digital content. Significantly fewer resources are available to medical training programs for creating and maintaining websites. Often, those tasked with managing these websites must balance this responsibility with numerous other clinical and administrative tasks. As a result, many residency program websites fail to offer comprehensive information related to their residency program or fail to have a website at all [2-6].

Residency program-specific website managers must understand how, when, and why their website is being accessed to allow for efficient web-based communications. Unfortunately, little is known regarding when and for what purposes residency program-specific websites are being accessed. Such data can be utilized to create an efficient model for editing a program's website and prioritize the update of commonly accessed content in a timely manner. Thus, the objective of our study was to describe trends in the access patterns of a residency program-specific website. 


\section{Materials And Methods}

This study was a retrospective analysis using website analytics at one large urban Accreditation Council for Graduate Medical Education (ACGME)-accredited post-graduate year (PGY1)-PGY4 emergency medicine residency training program with 68 residents in training and rotations for both third and fourth-year medical students. Website analytics of the program website were performed using Squarespace ${ }^{\mathrm{TM}}$ across two academic years: from July 1, 2016 to June 30, 2018 [7]. Daily traffic was cataloged along with referral sources, page views, and device type used to access the website. The top five dates by daily traffic were specifically analyzed along with daily traffic trends during the residency interview season (October to February).

\section{Results}

Over the 24-month study period, there was an average of 45.8 unique visitors daily with 261.5 page views per day. Computer access accounted for $67.2 \%$ of website visits, mobile device for $29.6 \%$ of visits, and tablet for $3.1 \%$. Google searches accounted for $49.3 \%$ of visits, direct uniform resource locator entry for $41.8 \%$, and Bing searches for $2.4 \%$. The remaining $6.5 \%$ of visits were via other sources. The majority of visits (94.2\%) originated from within the United States with less than 1\% from each of Canada, India, the Republic of Korea, the United Kingdom, Russia, and other countries.

The most popular content by page-view (Figure 1) were "people" (68,987 visits), "home” (38,569), "clinical curriculum" (35,556), and "medical students" $(14,461)$. The five most-visited dates (Figure 2) were all related to medical student application processes including the opening of the Visiting Student Application Service (VSAS), the Electronic Residency Application Service (ERAS), and Match Day. During the interview season, peak visits occurred on the days immediately preceding a residency program interview date (Figure 3).

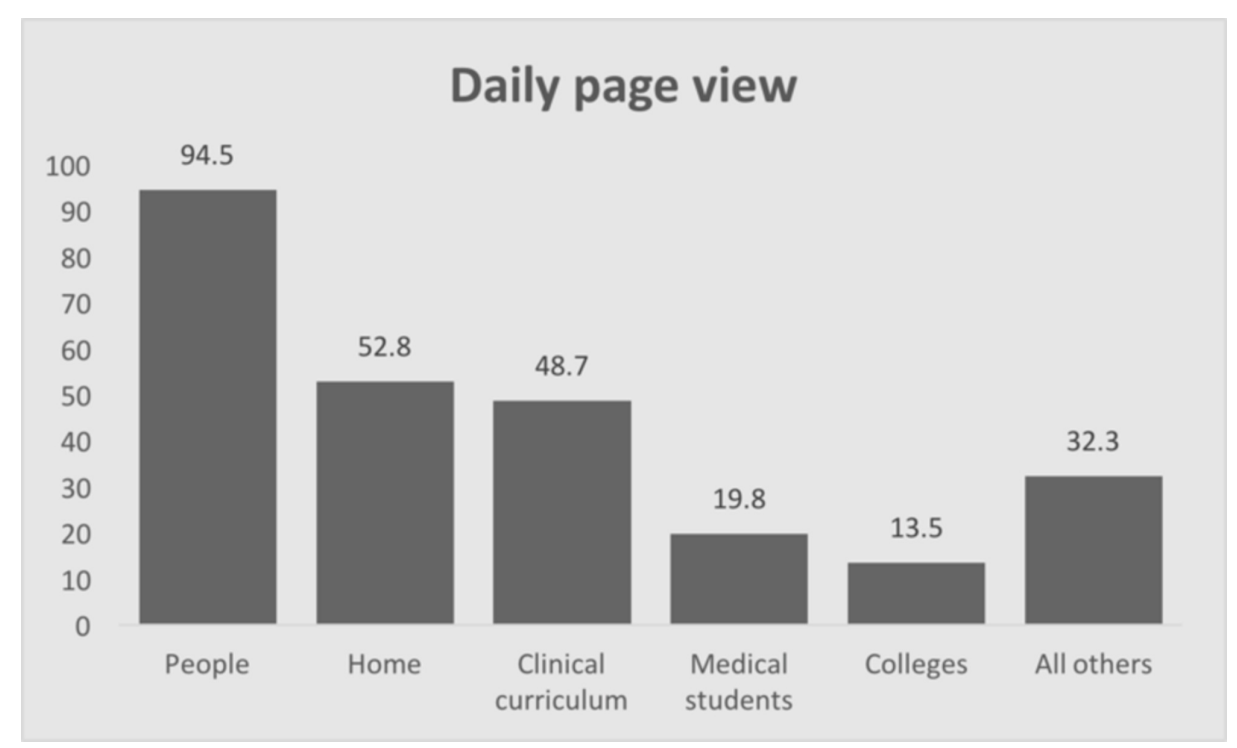

FIGURE 1: Daily website page views by page

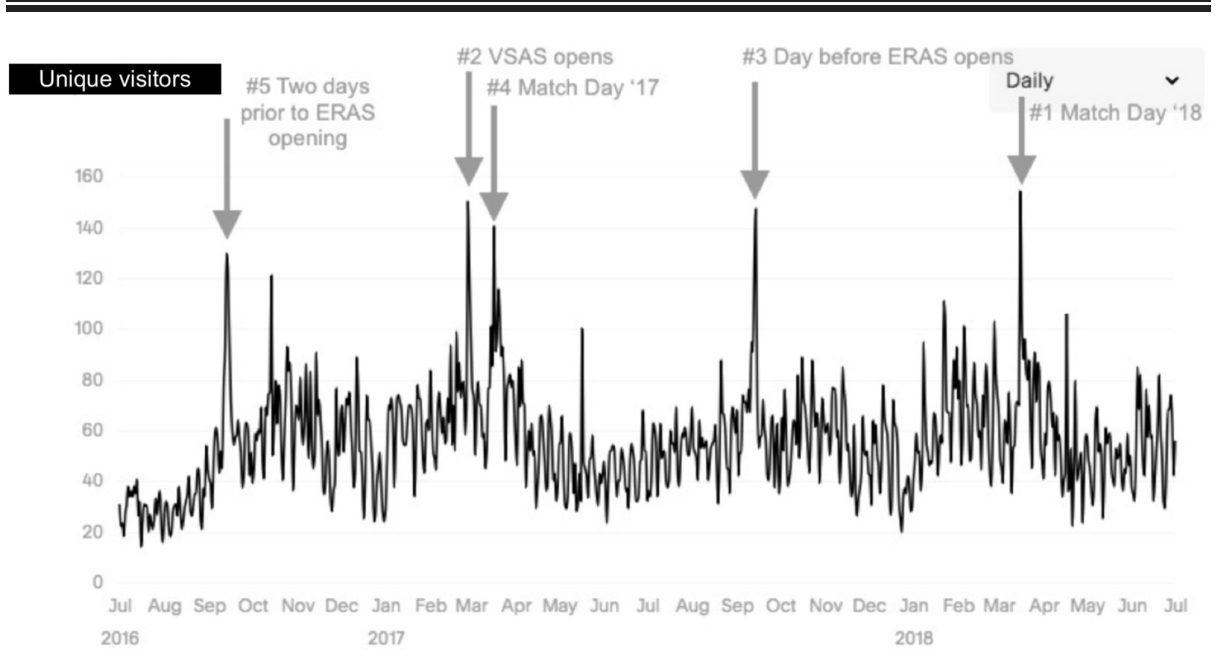




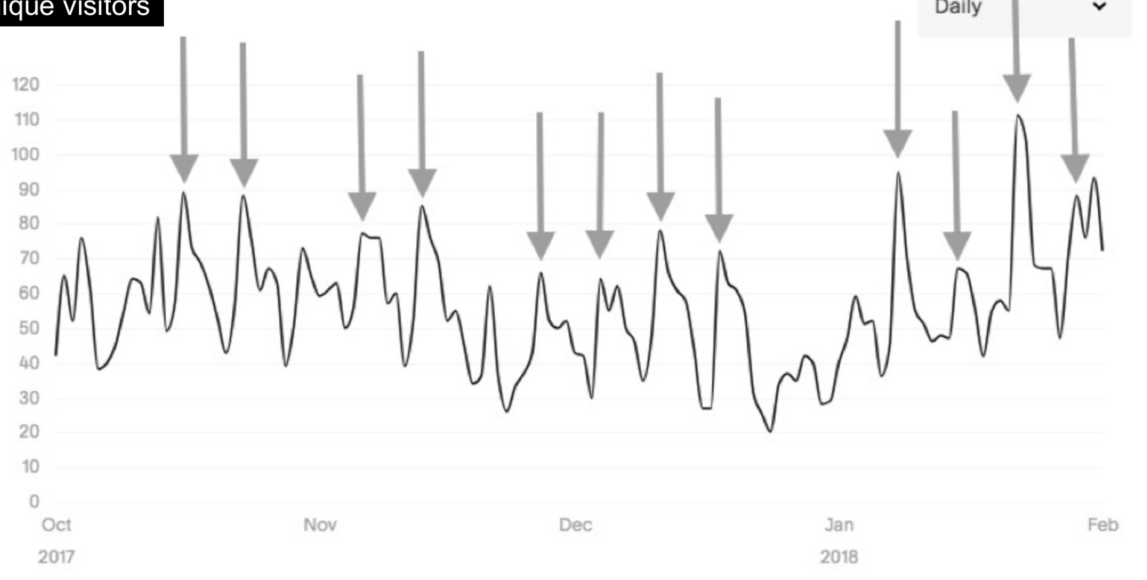

\section{FIGURE 3: Daily viewing trends during residency interview season: October to February}

Interview dates indicated by arrows

\section{Discussion}

Peak access to the residency program-specific website was related to medical student and prospective resident application processes along with Match Day. The days immediately preceding interview dates also corresponded to a sharp increase in website traffic. Medical students and potential residency program applicants are likely significant consumers of residency program-specific website content given peak website traffic tended to parallel medical student's fourth year away rotation and residency application dates. Website managers should consider this primary audience when creating content for their websites and make the content accessible and pertinent to medical students and prospective residency applicants.

While computers accounted for the majority of website traffic, about one-third of visits were via a mobile device or tablet. Website managers should thus ensure residency program websites are as mobile device compatible as possible. Additionally, most website traffic was directed via a search engine rather than a direct link from databases such as the Fellowship Residency Electronic Interactive Data Access System (FREIDA) or the ACGME. This finding was not unexpected as these databases have variation in link access to residency program-specific websites [8]. Programs should ensure their websites are easily discoverable through simple keywords used in search engines to increase the likelihood that potential applicants are directed to the correct website.

Data on peak traffic dates can help influence decisions about when website edits should take place. According to our study, this is ideally prior to the opening of the application cycles of VSAS and ERAS. As residency program website managers typically work with limited resources and often balance website-related responsibilities with other administrative or clinical duties, it is critical that changes to the website occur efficiently and in a way that will maximize the impact on website viewership.

With regard to page-view data, the most popular content accessed was the "people" section of the website. This section includes photographs of current residents and faculty and information regarding their medical school and other training. Efforts to keep these sections up to date and include information pertinent to prospective applicants should be prioritized. Interestingly, information regarding the program's curriculum was accessed much less often, at about half the frequency as the "people" section, which underscores the value prospective applicants may place on the backgrounds of their potential colleagues.

\section{Conclusions}

Residency program-specific websites appear to be accessed most commonly by medical students and prospective residency program applicants. Peak access times tended to cluster around medical student dates of importance such as the VSAS and ERAS application opening dates, Match Day, and the days prior to 
residency program interview dates. Residency program website managers can use these data to better understand the primary audiences of their residency program websites and determine when to update and upload new content to best inform and attract prospective residency program candidates.

\section{Additional Information}

\section{Disclosures}

Human subjects: All authors have confirmed that this study did not involve human participants or tissue. Animal subjects: All authors have confirmed that this study did not involve animal subjects or tissue. Conflicts of interest: In compliance with the ICMJE uniform disclosure form, all authors declare the following: Payment/services info: All authors have declared that no financial support was received from any organization for the submitted work. Financial relationships: All authors have declared that they have no financial relationships at present or within the previous three years with any organizations that might have an interest in the submitted work. Other relationships: All authors have declared that there are no other relationships or activities that could appear to have influenced the submitted work.

\section{References}

1. Oladeji LO, Yu JC, Oladeji AK, Ponce BA: How useful are orthopedic surgery residency web pages? . J Surg Educ. 2015, 72:1185-1189. 10.1016/j.jsurg.2015.05.012

2. Hansberry DR, Bornstein J, Agarwal N, McClure KE, Deshmukh SP, Long S: An assessment of radiology residency program websites. J Am Coll Radiol. 2018, 15:663-666. 10.1016/j.jacr.2017.11.010

3. Hashmi A, Policherla R, Campbell H, Khan FA, Schumaier A, Al-Mufarrej F: How informative are the plastic surgery residency websites to prospective applicants?. J Surg Educ. 2017, 74:74-78.

10.1016/j.jsurg.2016.08.002

4. Svider PF, Gupta A, Johnson AP, et al.: Evaluation of otolaryngology residency program websites . JAMA Otolaryngol Head Neck Surg. 2014, 140:956-960. 10.1001/jamaoto.2014.1714

5. Huang BY, Hicks TD, Haidar GM, Pounds LL, Davies MG: An evaluation of the availability, accessibility, and quality of online content of vascular surgery training program websites for residency and fellowship applicants. J Vasc Surg. 2017, 66:1892-1901. 10.1016/j.jvs.2017.08.064

6. Novin S, Yi PH, Vanderplas T, Yim D, Hong K: Integrated interventional radiology residency program websites: a development in progress. AJR Am J Roentgenol. 2018, 211:211-216. 10.2214/ajr.17.19008

7. Cook county hospital emergency medicine residency . (2020). Accessed: January 28, 2020: http://www.cookcountyem.com.

8. Wakefield DV, Manole BA, Jethanandani A, et al.: Accessibility, availability, and quality of online information for US radiation oncology residencies. Pract Radiat Oncol. 2016, 6:160-165. 10.1016/j.prro.2015.10.016 